July 2009

\title{
A Metastatic Middle Cerebral Artery Aneurysm Caused by an Intraluminal Bronchogenic Tumor Embolus
}

\author{
Ciro Randazzo MD, MPH \\ Ashwini Sharan MD \\ Thomas Jefferson University \\ James Harrop MD \\ Thomas Jefferson University \\ Lawrence C. Kenyon \\ Thomas Jefferson University \\ Robert H. Rosenwasser MD \\ Thomas Jefferson University
}

Follow this and additional works at: https://jdc.jefferson.edu/jhnj

\section{Let us know how access to this document benefits you}

\section{Recommended Citation}

Randazzo, Ciro MD, MPH; Sharan MD, Ashwini; Harrop, James MD; Kenyon, Lawrence C.; and Rosenwasser MD, Robert H. (2009) "A Metastatic Middle Cerebral Artery Aneurysm Caused by an Intraluminal Bronchogenic Tumor Embolus," JHN Journal: Vol. 4 : Iss. 3 , Article 6.

DOI: https://doi.org/10.29046/JHNJ.004.3.006

Available at: https://jdc.jefferson.edu/jhnj/vol4/iss3/6

This Article is brought to you for free and open access by the Jefferson Digital Commons. The Jefferson Digital Commons is a service of Thomas Jefferson University's Center for Teaching and Learning (CTL). The Commons is a showcase for Jefferson books and journals, peer-reviewed scholarly publications, unique historical collections from the University archives, and teaching tools. The Jefferson Digital Commons allows researchers and interested readers anywhere in the world to learn about and keep up to date with Jefferson scholarship. This article has been accepted for inclusion in JHN Journal by an authorized administrator of the Jefferson Digital Commons. For more information, please contact: JeffersonDigitalCommons@jefferson.edu. 


\section{A Metastatic Middle Cerebral Artery Aneurysm Caused by an Intraluminal Bronchogenic Tumor Embolus}

\author{
Ciro G. Randazzo, MD', Ashwini D. Sharan, MD ${ }^{1,3}$, James S. Harrop, MD $^{1,3}$, \\ Ron P. Benitez, MD², Lawrence C. Kenyon, MD², \\ Robert H. Rosenwasser, MD, FACS, FAHA ${ }^{4,5}$ \\ ${ }^{1}$ Resident (2009), Department of Neurological Surgery, Thomas Jefferson University Hospital \\ ${ }^{2}$ Resident (1999), Department of Neurological Surgery, Thomas Jefferson University Hospital \\ ${ }^{3}$ Associate Professor (2009), Department of Pathology, Anatomy and Cell Biology Thomas \\ Jefferson University \\ ${ }^{4}$ Professor (1999), Department of Neurosurgery, Thomas Jefferson University \\ ${ }^{5}$ FACS, FAHA, Professor and Chair (2009), Department of Neurosurgery, \\ Thomas Jefferson University (2009)
}

This is an unpublished paper from 2000. The main author was Dr. Sharan, then a resident and now a faculty member. Readers interested in current knowledge in the area should visit www.pubmed.gov and search the medical subject heading terms "Intracranial aneurysm" and "brain neoplasms."

\section{Abstract}

Objective and Importance: To describe the clinical presentation and neuropathological findings of metastatic cerebral aneurysms of bronchogenic origin. Metastatic bronchogenic cerebral aneurysms are exceptionally rare and have only been reported in association with high grade hemorrhage.

Clinical Presentation: One patient presenting with a history of headache, speech difficulty, left-sided "numbness", left seventh nerve palsy and left hemiparesis was found to have intraparenchymal and subarachnoid hemorrhage with an aneurysm of the right distal Sylvian middle cerebral artery.

Intervention: Pterional craniotomy with excision of mycotic segment. Surgical specimen sent to pathology for routine histology and immunohistochemistry.

Conclusion: Patients with metastatic cerebral aneuryms of bronchogenic origin usually present with subarachnoid hemorrhage, contrary to prior observations that "hemorrhage from neoplasia-induced aneurysms is paradoxically rare." A tumor embolus should be considered in the differential diagnosis of a mycotic aneurysm.

Cerebral aneurysms have been reported as a complication of primary extracranial neoplasms. The preponderance of such cases has been associated with cardiac myxomas and choriocarcinomas. Olmsted and $\mathrm{McGee}^{5}$ report approximately a $45 \%$ systemic embolization rate, half of which may be cerebral, in patients with left atrial myxoma. Weir et al. ${ }^{7}$ described mycotic aneurysms from choriocarcinoma as specifically being distal, lobulated, and fusiform. Pullar et al. ${ }^{6}$ reported a series of eight cases of metastatic cerebral aneurysms secondary to choriocarcinoma.

There have only been four reported cases of metastatic cerebral aneurysm of bronchogenic origin ${ }^{1-4}$ The first case was described in $1982 \mathrm{by} \mathrm{Ho}^{2}$. Ho described a fatal intracerebral hemorrhage associated with an aneurysm in the medial aspect of the occipital lobe. Histologically, the lumen of the vessel contained collections of neoplastic cells that had invaded the vessel wall and destroyed the native cytoarchitecture. Kochi et al. ${ }^{3}$ described an intracerebral hematoma from rupture of a metastatic cerebral bronchogenic aneurysm in a cortical branch of the left posterior temporal artery. Murata et al. ${ }^{4}$ reported intracerebral hematoma from rupture of a metastatic cerebral bronchogenic aneurysm from a cortical branch of the posterior cerebral artery. Gliemroth et al. ${ }^{1}$ reported recurrent and fatal subarachnoid hemorrhage from rupture of a metastatic cerebral bronchogenic aneurysm of the anterior inferior cerebellar artery. This patient also developed a mycotic neoplastic aneurysm in the contralateral anterior inferior cerebellar artery.
Previous reports ${ }^{*}$ of metastatic cerebral aneurysms postulated a low rate of hemorrhage. The four cases reported to date of metastatic cerebral bronchogenic aneurysm and our case, representing the fifth, have all presented with high grade subarachnoid hemorrhage.

\section{Case Report}

A 43-year-old female with a history of hypertension, asthma, intravenous drug abuse, hepatitis, a right apical lung nodule and a significant smoking history acutely presented to the Emergency Department complaining of speech difficulty and left sided "numbness." Review of systems discovered a transient headache one week and one month prior to presentation. Physical examination demonstrated 4 out of 5 strength in the left upper and lower extremity on the left with hyperreflexia and an ipsilateral Babinski sign.

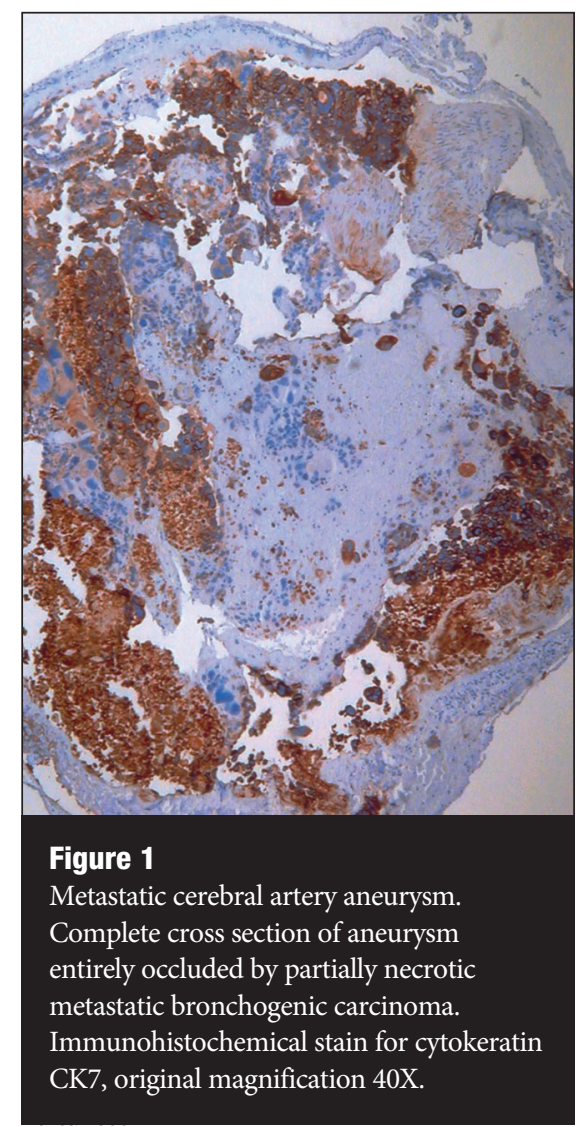


CT of the head was significant for Grade IV subarachnoid hemorrhage and a small intracerebral hemorrhage.

A transfemoral cerebral angiogram revealed a right distal middle cerebral artery aneurysm. No other aneurysms were discovered. Subsequently, the patient underwent a right pterional craniotomy with excision of a right middle cerebral artery aneurysm.

The resected portion of the middle cerebral artery sent to the pathologylab was i.dentified as a highly anaplastic intraluminal neoplasm that was likely metastatic in origin. Immunohistochemical staining was strongly positive for cytokeratins AE1, CK7 (Figure 1) and CAM5.2 (Figure 2). Hematoxylin and eosin staining demonstrated tumor embolus with invasion through the internal elastic membrane of the middle cerebral artery (Figure 3). Based on these results and the patient's known lung nodule, it was concluded that the specimen represented a metastatic carcinoma most likely from the lung.

A multi-disciplinary team was assembled to further investigate and treat the patient for a primary lung carcinoma. The final impression of the oncologist was that the patient's metastatic anaplastic carcinoma was most likely from her lung. The patient underwent whole brain irradiation and thoracic surgery was consulted for an open lung biopsy.

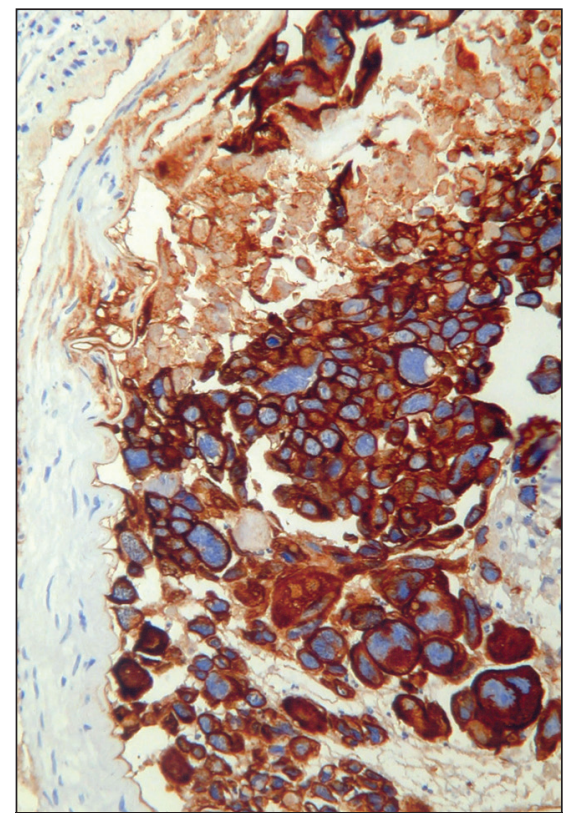

Figure 2

Metastatic cerebral artery aneurysm.

Tumor embolus adherent to wall of artery. Immunohistochemical stain for cytokeratin CAM5.2, original magnification 200X.

Table 1.

\begin{tabular}{|c|c|c|c|c|}
\hline Author & Demographics & Type of Cancer & Location & Complications \\
\hline Ho (2) & 68 , male & Bronchogenic & $\begin{array}{l}\text { Right Posterior } \\
\text { Cerebral A. }\end{array}$ & $\begin{array}{l}\text { Hemorrhage, } \\
\text { Rupture }\end{array}$ \\
\hline Murata et al (4) & 63 , male & Small Cell (lung) & $\begin{array}{l}\text { Anomalous } \\
\text { Artery }\end{array}$ & Hematoma \\
\hline Kochi et al (3) & 56 , male & $\begin{array}{l}\text { Undifferentiated } \\
\text { Squamous Cell (lung) }\end{array}$ & $\begin{array}{l}\text { Left Posterior } \\
\text { Temporal A. }\end{array}$ & $\begin{array}{l}\text { Hematoma, } \\
\text { Rupture }\end{array}$ \\
\hline Gliemroth et al (1) & 38 , female & $\begin{array}{l}\text { Adenocarcinoma } \\
\text { (lung) }\end{array}$ & $\begin{array}{l}\text { Bilateral Anterior } \\
\text { Inferior Cerebellar A. }\end{array}$ & $\begin{array}{l}\text { Hematoma } \\
\text { Rupture }\end{array}$ \\
\hline Current study & 43 , female & Bronchogenic & $\begin{array}{l}\text { Right Middle } \\
\text { Cerebral A. }\end{array}$ & Hemorrhage \\
\hline
\end{tabular}

\section{Discussion}

Cerebral aneurysms due to metastatic tumor emboli are quite rare. In $\mathrm{Ho's}^{2}$ early 1982 report of metastatic cerebral aneurysm of bronchogenic origin, he notes 23 documented cases of non-bronchogenic cerebral metastatic aneurysms. Approximately $70 \%$ of these cases were due to cardiac myxomas and $22 \%$ from choriocarcinomas.

Since the publication of this article there have been three other cases of metastatic lung cancer causing cerebral aneurysms $\mathrm{s}^{3-5}$. The currently reported case represents the fifth individual.

The small number of cases which have been reported limit our ability to characterize these metastatic aneurysms (Table 1). The documented cases do not demonstrate gender or age as risk factors for the development of these aneurysms. Additionally, the histologic subtype of bronchogenic carcinoma does not

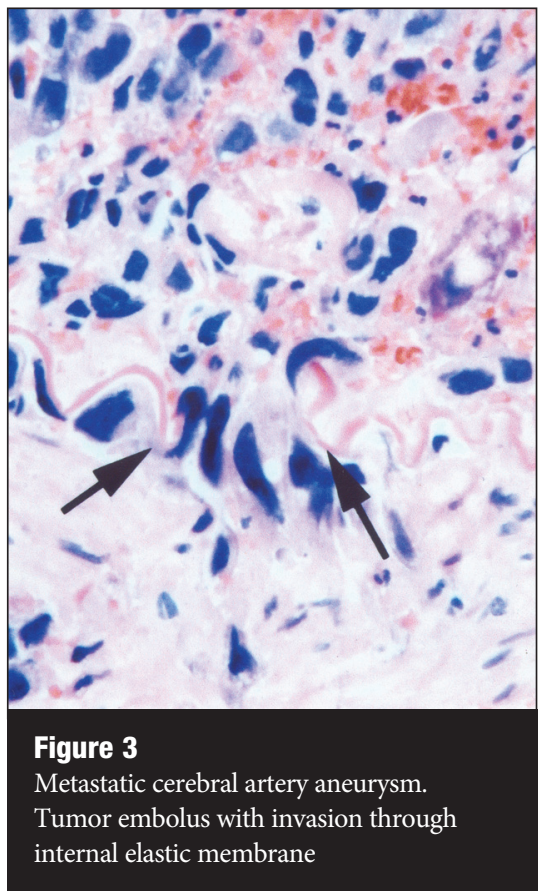

appear to favor neoplastic aneurysms, as both squamous and small-cell lung carcinoma have been identified in tumor emboli. It is not evident that a particular artery or location has a greater chance of developing a neoplastic aneurysm.

One observation that is clear is that all of the reported cases have been complicated by hemorrhage. It is unclear whether it is an inherent property of the primary carcinoma that results in hemorrhage or if observation bias results in the discovery of these aneurysms only when they bleed. If these aneurysms were often present without bleeding; however, they would most likely be reported in postmortem studies as have emboli from cardiac myxomas and choriocarcinomas.

\section{Conclusion}

The present case represents a rare, yet documented complication of primary bronchogenic carcinoma. Since the first case was described by Ho in 1982, several other cases have been identified. The limited number of cases prohibits identification of clear patterns. The recognition of neoplastic aneurysm formation as a devastating complication of bronchogenic carcinoma is necessary in the differential diagnosis of mycotic aneurysms.

\section{References}

1. Gliemroth J, Nowak G, Kehler U, Arnold H, Gaebel C: Neoplastic cerebral aneurysm from metastatic lung adenocarcinoma associated with cerebral thrombosis and recurrent subarachnoid haemorrhage. J Neurol Neurosurg Psychiatry 66: 246-247, 1999.

2. Ho KL: Neoplastic aneurysm and intracranial hemorrhage. Cancer 50: 2935-2940, 1982

3. Kochi N, Tani E, Yokota M, Nakaya Y: Neoplastic cerebral aneurysm from lung cancer. Case report. J Neurosurg 60: 640-643, 1984.

4. Murata J, Sawamura Y, Takahashi A, Abe H, Saitoh H: Intracerebral hemorrhage caused by a neoplastic aneurysm from small-cell lung carcinoma: case report. Neurosurgery 32 : 124-126, 1993.

5. Olmsted WW, McGee TP: The pathogenesis of peripheral aneurysms of the central nervous system: a subject review from the AFIP. Radiology 123: 661-666, 1977.

6. Pullar M, Blumbergs PC, Phillips GE, Carney PG: Neoplastic cerebral aneurysm from metastatic gestational choriocarcinoma. Case report. J Neurosurg 63: 644-647, 1985.

Weir B, MacDonald N, Mielke B: Intracranial vascular complications of choriocarcinoma. Neurosurgery 2: 138-142, 1978. 